\title{
Preliminary Evidence for the Cross-Cultural Utility of the Type D Personality Construct in the Ukraine
}

\author{
Susanne S. Pedersen • Andriy Yagensky • \\ Otto R. F. Smith • Oksana Yagenska • \\ Volodymyr Shpak • Johan Denollet
}

Published online: 20 February 2009

(C) The Author(s) 2008. This article is published with open access at Springerlink.com

\begin{abstract}
Background Type D personality is a risk indicator in cardiac patients. The validity and reliability of the Type D Scale (DS14) have been confirmed in Western Europe but not outside this context.

Purpose We examined the structural, convergent, and divergent validity and the reliability of the DS14 in the Ukrainian setting.

Method Healthy Ukrainian respondents $(n=250)$ completed the DS14, the Eysenck Personality Questionnaire, the State Trait Anxiety Inventory, and the Beck Depression Inventory. A subsample $(n=57)$ completed the DS14 again after 4 weeks.

Results The prevalence of Type D personality was $22.4 \%$. The two-factor structure and the validity of the DS14 were confirmed. The DS14 subscales were internally consistent (Cronbach's $\alpha=0.86 / 0.71$; mean inter-item correlation= $0.48 / 0.27)$ and stable over a 4 -week period $(r=0.85 / 0.63)$. Type D individuals had significantly higher mean scores on
\end{abstract}

S. S. Pedersen · O. R. F. Smith · J. Denollet

Center of Research on Psychology in Somatic diseases (CoRPS),

Tilburg University,

Tilburg, The Netherlands

A. Yagensky

Lutsk City Hospital,

Lutsk, Ukraine

O. Yagenska $\cdot$ V. Shpak

Volyn State University,

Lutsk, Ukraine

S. S. Pedersen $(\square)$

CoRPS, Department of Medical Psychology, Tilburg University,

Room P506, Warandelaan 2, P.O. Box 90153, 5000 LE Tilburg,

The Netherlands

e-mail: s.s.pedersen@uvt.nl anxiety $(p<0.001)$, depressive symptoms $(p<0.001)$, and negative affect $(p<0.001)$, and lower scores on positive affect $(p<0.001)$ compared to non-Type D individuals. Conclusion Preliminary evidence suggests that the Ukrainian DS14 is a valid and reliable measure. Future studies are warranted to test the utility of the scale in cardiac patients in the Ukraine, including whether Type D also predicts adverse health outcomes beyond the boundaries of Western Europe.

Keywords Anxiety · Cross-cultural validity. Depression . Positive affect · Type D personality

\section{Introduction}

The distressed (Type D) personality is a risk indicator for multiple health outcomes in patients with cardiovascular disease (CVD), including mortality, morbidity, impaired health status, emotional distress, and exhaustion [1, 2]. The impact of Type D on CVD prognosis is independent of biomedical risk factors, including disease severity as measured by left ventricular ejection fraction, indicating that the cardio-toxicity of Type D cannot be attributed to these patients being more severely ill [3-5]. Similarly, Type D personality exerts its deleterious effects on health outcomes independent of treatment [6-9] and mood states, such as anxiety and depression $[3,5,6]$.

The Type D personality construct was originally developed in Belgian patients with ischemic heart disease, but the value of the construct has subsequently been confirmed in patients with peripheral arterial disease [10], chronic heart failure [11], arrhythmia [12], and in patients treated with revascularization procedures [5, 7, 10, 12-14]. Type D personality is defined by the co-occurrence of a high score 
on the two normal and stable personality traits, negative affectivity and social inhibition [15]. Type D patients tend to experience increased negative emotions while not expressing these emotions, with these patients typically having a gloomy view of life, feeling sad, being closed, and feeling inhibited in social interactions [15].

Type D personality can be assessed with the brief, valid, and reliable Type D Scale (DS14) [15]. Despite current preliminary evidence on Type $\mathrm{D}$ as a risk indicator in CVD, with Type D fulfilling several external criteria set out for evaluating new risk indicators and risk markers [1] and the validity and reliability of the scale being established in Belgian [15], German [16], Italian [17], and Danish [18] populations, its generalizability has not yet been investigated outside the Western European context. Hence, in the current study, we examined the structural, convergent, and divergent validity, and the reliability of the Type D Scale in the Ukrainian setting.

\section{Methods}

\section{Participants}

Of 281 students approached for participation from Volyn State University, Lutsk, Ukraine, 250 (89\%; 45.2\% men; mean age (years) $=20.9 \pm 3.4$ ) agreed to participate and completed a set of psychological questionnaires. The 250 students came from four disciplines, that is Physical Rehabilitation (57.6\%), Computer Engineering (14.0\%), Marketing (15.2\%), and Law (13.2\%). A subsample of 57 students completed the DS14 again at 4 weeks in order to examine the test-retest stability of the scale. The protocol was approved by the ethics committee of Lutsk City Hospital. All participants provided written informed consent, and the study was carried out in accordance with the Helsinki Declaration.

\section{Materials}

\section{Type D Personality}

We used the DS14 to evaluate Type D personality, which was translated into the Ukrainian language according to standard procedures [15]. The 14 items are divided into two seven-item subscales, that is, negative affectivity (e.g. "I often feel unhappy") and social inhibition (e.g. "I am a closed person") [15]. Responses to items are indicated on a five-point Likert scale from 0 (false) to 4 (true) (score range 0-28 for each subscale). Type D caseness is derived on the basis of a standardized cut-off $\geq 10$ on both subscales [15], with item response theory showing that all items have the highest measurement precision around this cut-off [19]. The
DS14 has good psychometric properties, with Cronbach's $\alpha=0.88 / 0.86$ and 3-month test-retest reliability $r=0.72$ / 0.82 for the negative affectivity and social inhibition subscales, respectively [15].

\section{Neuroticism and Extroversion}

Neuroticism (24 items) and extroversion (24 items) were assessed with the Eysenck Personality Questionnaire (EPQ; [20]). These subscales were included in order to examine the construct validity of the DS14, as they comprise theoretically similar constructs to the negative affectivity and social inhibition subscales of the DS14. All items are answered with 0 (no) or 1 (yes), with a high score indicating more of the personality trait. The validity and reliability of the two subscales have proven satisfactory in the Ukrainian setting [20].

\section{Anxiety}

The State-Trait Anxiety Inventory (STAI) is a 40-item measure that assesses state and dispositional anxiety [21, 22]. Items contribute with 20 items to each state and trait subscale and are answered on a four-point Likert scale from 1 (not at all) to 4 (very much so) (score range, 20-80), with a higher score indicating more anxiety. For the current study, we only used the state version of the STAI to examine the construct validity of the DS14. The STAI is a valid and reliable measure, with Cronbach's $\alpha$ ranging from 0.89 to 0.94 [21].

\section{Depression}

The 21-item Beck Depression Inventory (BDI), assessing cognitive, affective, and somatic symptoms of depression, was included in the current study to examine the construct validity of the DS14 $[23,24]$. The BDI is a frequently used measure of depressive symptoms in CVD patients and has been shown to predict mortality [25]. Items are answered on a three-point scale from 0 to 3 (score range, 0-63), with a higher score indicating more severe depressive symptomatology. The psychometric properties of the BDI are good, with Cronbach's $\alpha$ ranging from 0.76 to 0.95 in psychiatric populations and 0.73 to 0.92 in non-psychiatric populations [25].

\section{Negative and Positive Affect}

The Global Mood Scale (GMS) is a 20-item measure of negative and positive affect, with ten items contributing to each subscale [26]. Items are rated on a five-point Likert scale ranging from 0 (not at all) to 4 (extremely), with a score range from 0 to 40 for both subscales. The GMS is an 
internally consistent measure, with Cronbach's $\alpha$ ranging from 0.87 to 0.94 for the negative affect subscale and $0.85-$ 0.91 for the positive affect subscale [26-28]. The GMS has been shown to be responsive to tap treatment-related changes following cardiac rehabilitation in CVD patients [27]. The GMS was included to evaluate the construct validity of the DS14.

\section{Statistical Analyses}

Prior to statistical analyses, missing items were replaced with the mean of the completed items belonging to that subscale. The number of missing on the items of the psychological questionnaires was less than $2 \%$ on any given item. Nominal variables were compared with the chisquare test and continuous variables with Student's $t$ test for independent samples. Exploratory factor analysis (EFA) with varimax rotation was used to examine the structural validity of the DS14. A higher order factor analysis of scale scores (i.e., the DS14, EPQ, STAI, BDI, and GMS) and Pearson's correlations were used to examine the convergent and divergent construct validity of the DS14. For both factor analyses, the scree plot was used to determine the number of factors to extract. Confirmatory factor analysis (CFA) was used to test the factor structure found with EFA. The $\chi^{2}$, Tucker-Lewis Index (TLI $>0.90$ acceptable; [29]), the Comparative Fit Index (CFI: $>0.90$ acceptable; [30]) and the root mean square error of approximation (RMSEA $<0.08$ acceptable; [31]) were used as goodness-of-fit indices. The internal consistency of the DS14 subscales was assessed with Cronbach's $\alpha$ and with the mean interitem correlation (MIIC). MIIC was used in addition to Cronbach's $\alpha$, since Cronbach's $\alpha$ is highly dependent on the number of items in a scale and hence prone to be inflated when the number of items is high. MIIC should fall in an optimal range between 0.20 to 0.50 [32] but should be no less than 0.15 [33]. The temporal stability of the DS14 subscales was examined with Pearson's correlations and paired $t$ tests. Mean scores on anxiety, depression, negative affect (GMS), and positive affect (GMS) stratified by Type D personality were analyzed with multivariate analysis of variance (MANOVA) to adjust for multiple comparisons. All tests were two-tailed. AMOS 7.0 was used to conduct the CFA. All other analyses were performed using SPSS 14.0 for Windows.

\section{Results}

Prevalence of Type D Personality

The prevalence of Type D personality in the Ukrainian sample was $22.4 \%$ (56/250). The prevalence of Type D was higher in women compared to men $[27.7 \%(38 / 137)$ vs $15.9 \%(18 / 113) ; p=0.038]$, but Type D and non-Type D individuals did not differ on mean age (years) $(20.82 \pm 3.47$ vs $20.93 \pm 3.32 ; p=0.84$ ).

\section{Structural Validity of the Ukrainian DS14}

The Kaiser-Meyer-Olkin measure of sampling adequacy $(0.857)$ and the Bartlett's test of sphericity $(<0.001)$ showed that the data fulfilled the assumptions for carrying out a factor analysis. The results confirmed the two-factor structure of the DS14, as indicated by the scree plot (Fig. 1) and the factor loadings (Table 1, left), although the factor loadings for items 3 and 11 were significantly smaller than for any of the other items. This two-factor model accounted for $48.8 \%$ (factor I, $36.0 \%$; factor II, $12.7 \%$ ) of the variance.

The two-factor solution derived from the EFA was validated using the same sample on which the EFA was done. Figure 2 shows the final solution of the CFA. The initial solution without correlated errors resulted in a poor fit both from a statistical $\left(\chi^{2}=198 ; d f=76, p<0.001\right)$ and descriptive point of view (TLI $=0.88$; CFI $=0.89$; RMSEA $=0.08$ ). However, examination of the standardized residual covariances revealed that $92.4 \%$ (97 out of 105) of the observed (co)variances were well explained by the initial model. A relatively large standardized residual covariance (3.27) was found between items 2 and 12 , which both reflect worry. This suggests that the response to item 12 is somewhat influenced by the response to item 2. Therefore, we assumed correlation between the error terms of these items, resulting in an improved and adequate descriptive fit (TLI $=0.91$; CFI $=$ 0.93; RMSEA $=0.07)$ of the model. However, the statistical fit of this model remained poor $\left(\chi^{2}=159 ; d f=75, p<\right.$ $0.001)$. The estimated unstandardized regression weights

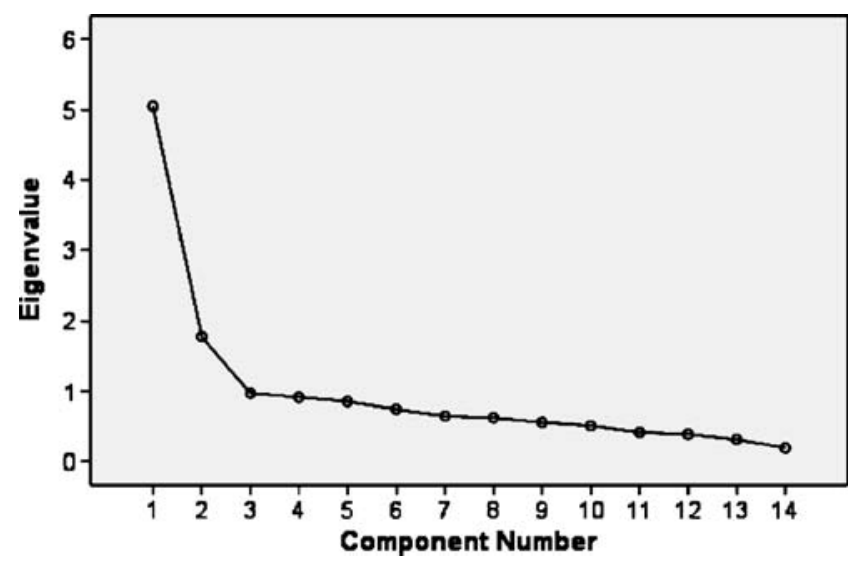

Fig. 1 Scree plot showing the eigenvalues for the DS14 factors 
Table 1 Structural validity and internal consistency of the Ukrainian DS14

\begin{tabular}{|c|c|c|c|c|}
\hline \multicolumn{2}{|c|}{ DS14 items } & \multirow[t]{2}{*}{ Factor $\mathrm{I}^{\mathrm{a}}$} & \multirow[t]{2}{*}{ Factor $\mathrm{II}^{\mathrm{a}}$} & \multirow[t]{2}{*}{ Corrected item-total correlations } \\
\hline \multicolumn{2}{|c|}{ Negative affectivity } & & & \\
\hline 2 & I often make a fuss about unimportant things & 0.71 & -0.02 & 0.57 \\
\hline 4 & I often feel unhappy & 0.76 & 0.08 & 0.55 \\
\hline 5 & I am often irritated & 0.77 & 0.09 & 0.66 \\
\hline 7 & I take a gloomy view of things & 0.53 & 0.24 & 0.46 \\
\hline 9 & I am often in a bad mood & 0.76 & 0.30 & 0.73 \\
\hline 12 & I often found myself worrying about something & 0.74 & 0.17 & 0.66 \\
\hline 13 & I am often down in the dumps & 0.77 & 0.23 & 0.72 \\
\hline \multicolumn{5}{|c|}{ Eigenvalue $=5.05$} \\
\hline \multicolumn{2}{|c|}{ Internal consistency (Cronbach's $\alpha)=0.86$} & & & $\mathrm{MICC}=.48$ \\
\hline \multicolumn{5}{|c|}{ Social inhibition } \\
\hline 1 & I make contact easily when I meet people ${ }^{\mathrm{b}}$ & 0.04 & -0.71 & 0.45 \\
\hline 3 & I often talk to strangers & 0.19 & -0.46 & 0.20 \\
\hline 6 & I often feel inhibited in social interactions ${ }^{\mathrm{b}}$ & 0.40 & 0.62 & 0.53 \\
\hline 8 & I find it hard to start a conversation & 0.28 & 0.69 & 0.57 \\
\hline 10 & I am a closed kind of person & 0.25 & 0.62 & 0.49 \\
\hline 11 & I would rather keep other people at a distance & 0.25 & 0.38 & 0.31 \\
\hline 14 & When socializing, I don't find the right things to talk about & 0.23 & 0.60 & 0.47 \\
\hline \multicolumn{5}{|c|}{ Eigenvalue $=1.78$} \\
\hline Inte & consistency $($ Cronbach's $\alpha)=0.71$ & & & $\mathrm{MICC}=0.27$ \\
\hline
\end{tabular}

MICC mean inter-item correlation

${ }^{\mathrm{a}}$ Items assigned to a factor are presented in bold

${ }^{\mathrm{b}}$ Items need to be reversed prior to calculating the subscale score

and covariances of the model with correlated errors are displayed in Table 2.

\section{Convergent and Divergent Validity}

DS14 negative affectivity was positively correlated with related constructs, such as neuroticism, anxiety, depression, and negative affect, with the shared variance ranging from 24\% (anxiety) to 50\% (neuroticism; Table 3, left). Although the overlap in variance between DS14 negative affectivity and neuroticism was $50 \%$, this indicates that there are some overlaps but that the constructs are not identical. By contrast, DS14 negative affectivity was negatively correlated with constructs that are conceptually different, such as extroversion and positive affect, with shared variances of $7 \%$ and $10 \%$. There was an inverse relationship between DS14 social inhibition, extroversion, and positive affect, respectively, with shared variances of $30 \%$ and $19 \%$ (Table 3, left). By contrast, the shared variance between DS14 social inhibition and negative affect measures ranged from $9 \%$ to $20 \%$. Taken together, these results confirm the convergent and divergent validity of the DS14 negative affectivity and social inhibition subscales.
A higher factor analysis on scale scores further corroborated the construct validity of the DS14, with negative affectivity, neuroticism, anxiety, depressive symptoms, and negative affect loading on one factor, and social inhibition, extroversion, and positive affect loading on another factor (Table 3, right).

\section{Internal Consistency}

The internal consistency of the DS14 negative affectivity and social inhibition subscales, as measured by Cronbach's $\alpha$, were 0.86 and 0.71 , respectively (Table 1 , right). MICC for the negative affectivity and social inhibition subscales were 0.48 and 0.27 , respectively. Both measures of internal consistency conform to proposed guidelines, indicating a good internal consistency $[32,33]$.

Temporal Stability of the Type D construct

The 4-week test-retest reliability, as measured by Pearson's correlation in a subsample $(n=57)$, was $r=0.85$ for the negative affectivity and $r=0.63$ for the social inhibition subscales, respectively. A paired samples $t$ test using negative affectivity and social inhibition at baseline and 
retest showed no significant differences in scale scores over a 4-week period (negative affectivity, $t=0.064, d f=56 ; p=$ 0.95 ; social inhibition, $t=0.70, d f=56, p=0.49$ ). These results confirm the temporal stability of the DS14 during the course of 4 weeks.

Symptomatology and Affect Stratified by Type D Personality

Type D individuals had significantly higher mean scores on anxiety compared to non-Type D individuals $(49.13 \pm 8.39$ vs $41.35 \pm 7.33, p<0.001)$. Similarly, mean scores on depressive symptoms and negative affect were higher in Type D vs non-Type D individuals, whereas positive affect was lower in Type D individuals (Fig. 3). This further testifies to the construct validity of Type D personality in the Ukraine.

\section{Discussion}

This is the first study to show that the Type D personality construct is generalizable beyond the Western European

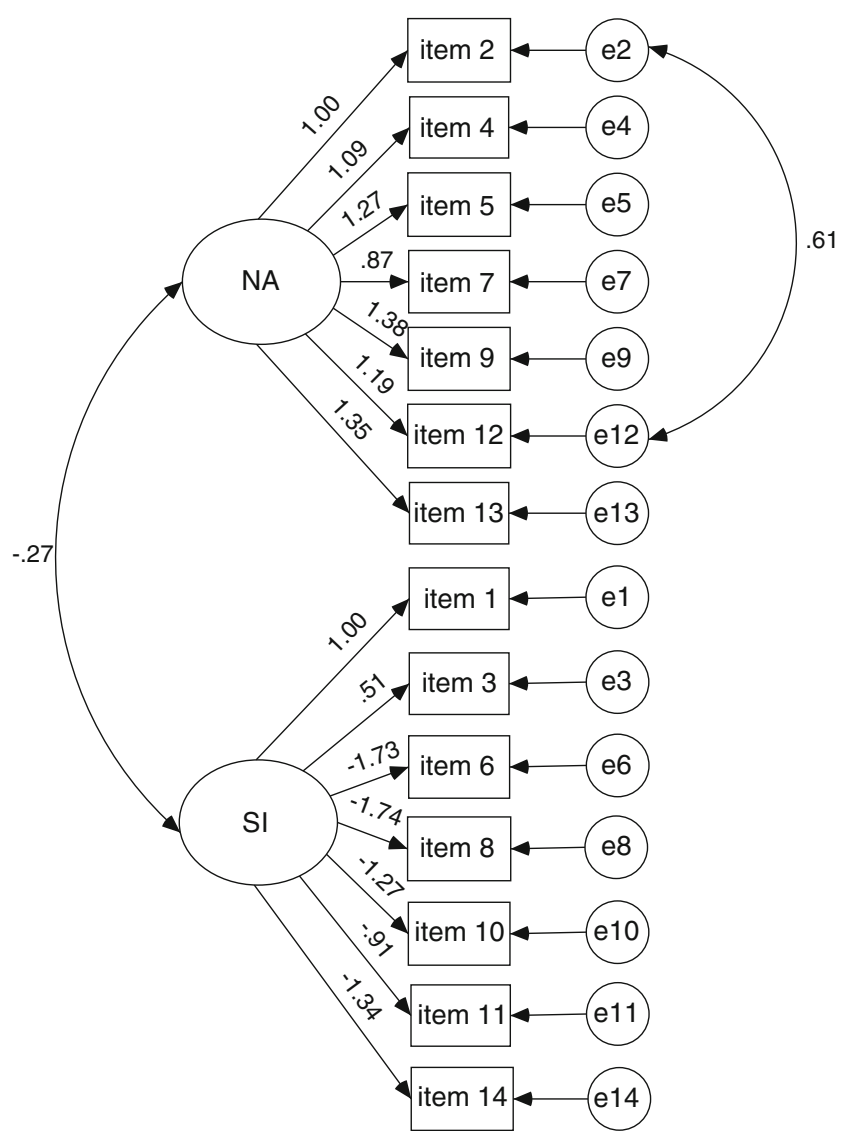

Fig. 2 Final confirmatory factor analysis model for the DS14. NA negative affectivity, SI social inhibition
Table 2 Estimated unstandardized regression weights and covariances for the confirmatory factor analysis model with correlated errors

\begin{tabular}{llrll}
\hline Item & Factor & Estimate & SE & $p$ value \\
\hline 1 & SI & 1.00 & - & - \\
2 & NA & 1.00 & - & - \\
3 & SI & 0.51 & 0.21 & 0.013 \\
4 & NA & 1.09 & 0.14 & $<0.001$ \\
5 & NA & 1.27 & 0.16 & $<0.001$ \\
6 & SI & -1.73 & 0.26 & $<0.001$ \\
7 & NA & 0.87 & 0.13 & $<0.001$ \\
8 & SI & -1.74 & 0.27 & $<0.001$ \\
9 & NA & 1.38 & 0.16 & $<0.001$ \\
10 & SI & -1.27 & 0.21 & $<0.001$ \\
11 & SI & -0.91 & 0.21 & $<0.001$ \\
12 & NA & 1.19 & 0.13 & $<0.001$ \\
13 & NA & 1.35 & 0.16 & $<0.001$ \\
14 & SI & -1.34 & 0.22 & $<0.001$ \\
Cov (NA, SI) & -0.27 & 0.06 & $<0.001$ \\
Cov (e2, e12) & 0.61 & 0.11 & $<0.001$ \\
\hline
\end{tabular}

setting, with the results providing preliminary evidence for the cross-cultural utility of the Type D personality construct in the Ukraine. The two-factor structure of the DS14 was confirmed in the Ukrainian setting, and the DS14 was shown to be a valid, reliable, and stable measure over a 4week period.

The results of the current study are consistent with those of previous validation studies of the Type D construct in Western European countries, including Belgium [15], Germany [16], Italy [17], and Denmark [18], showing that the Type D construct is valid and reliable. Nevertheless, the results indicate that the internal consistency of the social inhibition subscale of the Ukrainian version of the DS14 might be improved by replacing some of its items. These items may be culturally sensitive items and hence difficult to translate. An alternative explanation may be that these items have different connotations in different cultures, with some items not being culturally relevant outside the Western context. However, prior to making the decision whether to replace items of the DS14 Ukrainian version with alternative items, it would be important to have more data on this language version in its present form including in patients with somatic disease, such as CVD, in which the DS14 was originally developed.

In the current sample, the prevalence of Type D personality was $22.4 \%$, which compares to prevalence rates found in other studies in the general population and healthy samples, although there is some variation across samples $[10$, $15,16,18]$. In patients with CVD, prevalence rates range from $23 \%$ to $36 \%$, depending on whether the diagnosis is ischemic heart disease [9, 15, 34], chronic heart failure [11], or peripheral arterial disease [10]. 
Table 3 Correlation matrix and higher order factor analysis on scale scores (DS14, EPQ, STAI, BDI, and GMS)

\begin{tabular}{|c|c|c|c|c|c|c|c|c|c|c|c|}
\hline & & \multicolumn{8}{|c|}{ Correlation matrix } & \multicolumn{2}{|c|}{$\frac{\text { Higher-order }}{\text { Factor analysis }^{\mathrm{a}}}$} \\
\hline & & 1 & 2 & 3 & 4 & 5 & 6 & 7 & 8 & I & II \\
\hline 1 & DS14: Negative affectivity & - & & & & & & & & 0.83 & 0.21 \\
\hline 2 & DS14: Social inhibition & $0.45^{*}$ & - & & & & & & & 0.29 & 0.76 \\
\hline 3 & EPQ: Neuroticism & $0.71 *$ & $0.32 *$ & - & & & & & & 0.84 & 0.09 \\
\hline 4 & EPQ: Extroversion & $-0.26^{*}$ & $-0.55^{*}$ & $-0.16^{*}$ & - & & & & & -0.05 & -0.87 \\
\hline 5 & STAI: Anxiety & $0.49^{*}$ & $0.36^{*}$ & $0.51 *$ & $-0.33^{*}$ & - & & & & 0.63 & 0.38 \\
\hline 6 & BDI: Depression & $0.57 *$ & $0.40^{*}$ & $0.54 *$ & $-0.27^{*}$ & $0.49^{*}$ & - & & & 0.73 & 0.28 \\
\hline 7 & GMS: Negative affect & $0.55^{*}$ & $0.30^{*}$ & $0.49^{*}$ & $-0.21^{*}$ & $0.47 *$ & $0.52 *$ & - & & 0.76 & 0.13 \\
\hline 8 & GMS: Positive affect & $-0.31^{*}$ & $-0.44^{*}$ & $-0.31^{*}$ & $0.46^{*}$ & $-0.43^{*}$ & $-0.38^{*}$ & $-0.28^{*}$ & - & -0.26 & -0.72 \\
\hline
\end{tabular}

DS14 Type-D Scale, EPQ Eysenck Personality Questionnaire, STAI State-Trait Anxiety Inventory, BDI Beck Depression Inventory, GMS Global Mood Scale

${ }^{\mathrm{a}}$ Items assigned to a factor are presented in bold

$* p<0.01$

The utility of the Type D construct has been the subject of debate, with some questioning its novelty both in the context of existing personality theory and negative affect $[35,36]$. In the current study, the DS14 negative affectivity and social inhibition subscales were shown to be related to but nevertheless different from the personality traits neuroticism and extroversion. These findings are consistent with those of previous studies examining the validity of the DS14 $[15,16]$. Similarly, in the current study, the DS14

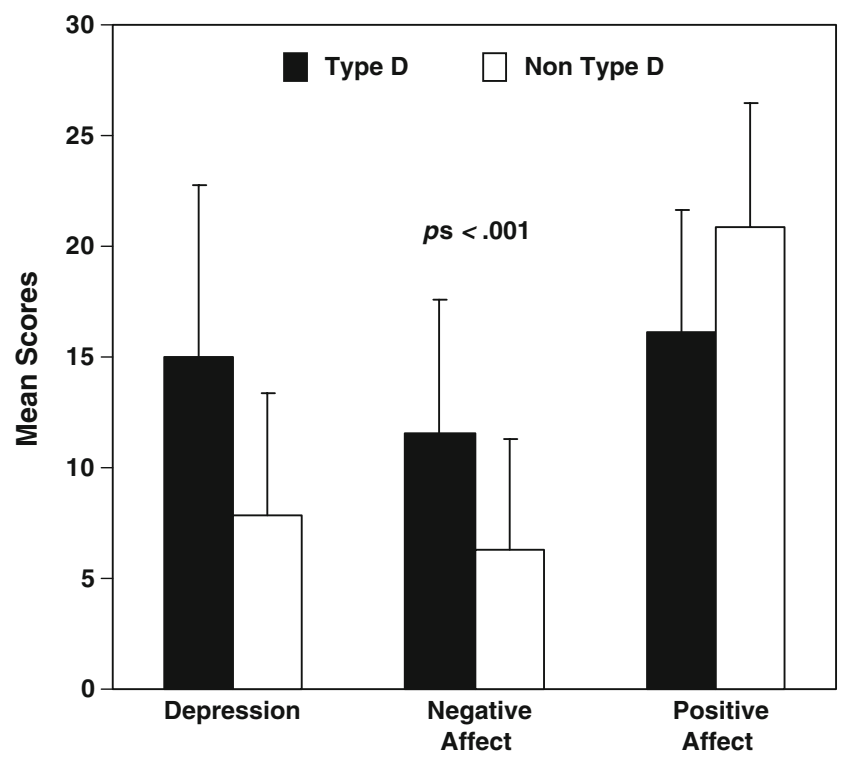

Fig. 3 Mean scores on mood states (i.e., depression, negative affect, and positive affect) stratified by Type D personality. MANOVA; standard deviations are presented on top of bars subscales correlated with measures of negative affect, but the shared variance did not extend beyond $32 \%$. Recent studies of patients treated with percutaneous coronary intervention in the drug-eluting stent area have also shown that Type D personality is different from negative affect, such as anxiety [37] and vital exhaustion [13]. In addition, a recent study lend further credence to the notion that it is Type D personality (i.e., the co-occurrence of negative affectivity and social inhibition) rather than the separate influence of the traits that incurs an increased risk on adverse prognosis [5]. In the latter study, social inhibition was shown to moderate the effect of negative affectivity on prognosis, with this influence being independent of mood states, such as anxiety and depressive symptoms, and traditional risk factors. Moreover, a recent seminal study has shown that Type D personality but not depressive symptoms, as measured by the Beck Depression Inventory, was associated with the cortisol awakening response [34]. Finally, others have recently shown that Type D personality has added value compared to traits, with both types (including Type D personality) and traits being independently associated with health outcomes in a large sample of older primary care patients [38].

This study has some limitations. First, the validity and reliability of the Ukrainian version of the DS14 was examined in a student population, and results may not be generalizable to patients with somatic disease, including CVD. Second, the test-retest reliability of the Ukrainian version of the DS14 was established only during the course of a 4-week period, which is relatively short. Nevertheless, this is the first study to show that the DS14 also has value beyond the Western European setting, using valid and 
reliable measures with which to examine the construct validity and reliability of the scale.

In conclusion, the validity and reliability of the DS14 was confirmed in a Ukrainian sample of students. These preliminary findings show that the Type D personality construct is not merely a Western European concept, but that the construct may also be generalized to Eastern Europe. Future studies are warranted to test the utility of the scale in CVD patients and patients with other somatic diseases in the Ukraine, including whether Type D also predicts adverse health outcomes in these patients.

Acknowledgments This research was supported by The Netherlands Organization for Scientific Research (NWO) with a VENI grant (45105-001) to Dr. SS Pedersen and a VICI grant (453-04-004) to Dr. J Denollet.

Open Access This article is distributed under the terms of the Creative Commons Attribution Noncommercial License which permits any noncommercial use, distribution, and reproduction in any medium, provided the original author(s) and source are credited.

\section{References}

1. Pedersen SS, Denollet J. Is type D personality here to stay? Emerging evidence across cardiovascular disease patient groups. Curr Cardiol Rev. 2006;2:205-13.

2. Compare A, Manozini GM, Molinari E. Type A, type D, angerprone behavior and risk of relapse in CHD patients. In: Molinari E, Compare A, Parati C, editors. Clinical psychology and heart disease. Italia: Springer; 2006. p. 187-215.

3. Denollet J, Brutsaert DL. Personality, disease severity, and the risk of long-term cardiac events in patients with decreased ejection fraction after myocardial infarction. Circulation. 1998;97:167-73.

4. Denollet J, Sys SU, Stroobant N, Rombouts H, Gillebert TC, Brutsaert DL. Personality as independent predictor of long-term mortality in patients with coronary heart disease. Lancet. 1996;347:417-21.

5. Denollet J, Pedersen SS, Ong AT, Erdman RA, Serruys PW, van Domburg RT. Social inhibition modulates the effect of negative emotions on cardiac prognosis following percutaneous coronary intervention in the drug-eluting stent era. Eur Heart J. 2006;27:171-7.

6. Denollet J, Vaes J, Brutsaert DL. Inadequate response to treatment in coronary heart disease: Adverse effects of type D personality and younger age on 5-year prognosis and quality of life. Circulation. 2000;102:630-5.

7. Pedersen SS, Lemos PA, van Vooren PR, Liu T, Daemen J, Erdman RAM, et al. Type D personality predicts death or myocardial infarction after bare metal stent or sirolimus-eluting stent implantation: a Rapamycin-Eluting Stent Evaluated At Rotterdam Cardiology Hospital (RESEARCH) registry sub-study. J Am Coll Cardiol. 2004;44:997-1001.

8. Al-Ruzzeh S, Athanasiou T, Mangoush O, Wray J, Modine T, George $\mathrm{S}$, et al. Predictors of poor mid-term health related quality of life after primary isolated coronary artery bypass grafting surgery. Heart. 2005;91:1557-62.
9. Pedersen SS, Middel B. Increased vital exhaustion among type D patients with ischemic heart disease. J Psychosom Res. 2001;51:443-9.

10. Aquarius AE, Denollet J, Hamming JF, De Vries J. Role of disease status and type D personality in outcomes in patients with peripheral arterial disease. Am J Cardiol. 2005;96:996-1001.

11. Schiffer AA, Pedersen SS, Widdershoven JW, Hendriks EH, Winter JB, Denollet J. Type D personality is independently associated with impaired health status and increased depressive symptoms in chronic heart failure. Eur J Cardiovasc Prevent Rehabil. 2005;12:341-6.

12. Pedersen SS, van Domburg RT, Theuns DA, Jordaens L, Erdman RA. Type D personality is associated with increased anxiety and depressive symptoms in patients with an implantable cardioverter defibrillator and their partners. Psychosom Med. 2004;66:714-9.

13. Pedersen SS, Daemen J, van de Sande M, Sonnenschein K, Serruys PW, Erdman RAM, et al. Type-D personality exerts a stable, adverse effect on vital exhaustion in PCI patients treated with paclitaxel-eluting stents. J Psychosom Res. 2007;62:447-53.

14. Pedersen SS, Denollet J, Ong ATL, Serruys PW, Erdman RAM, van Domburg RT. Impaired health status in type D patients following PCI in the drug-eluting stent era. Int $\mathrm{J}$ Cardiol. 2007;114:358-65.

15. Denollet J. DS14: Standard assessment of negative affectivity, social inhibition, and type D personality. Psychosom Med. 2005;67:89-97.

16. Grande G, Jordan J, Kümmel M, Struwe C, Schubmann R, Schulze F, et al. Evaluation of the German Type D Scale (DS14) and prevalence of the type D personality pattern in cardiological and psychosomatic patients and healthy subjects. Psychother Psychosom Med. 2004;54:413-22.

17. Gremigni $\mathrm{P}$, Sommaruga M. Pesonalità di Tipo $\mathrm{D}$, un costrutto rilevante in cardiologia. Studio preliminare di validazione del questionario italiano. Psicoter Cogn Comport. 2005;11:7-18.

18. Pedersen SS, Denollet J. Validity of the type D personality construct in Danish post-MI patients and healthy controls. J Psychosom Res. 2004;57:265-72.

19. Emons WHM, Meijer RR, Denollet J. Negative affectivity and social inhibition in cardiovascular disease: evaluating Type D personality and its assessment using item response theory. J Psychosom Res. 2007;63:27-39.

20. Pashukova TI, Dopira AI, Diakonov GV. Practical aspects in general psychology. Kiev: Znannia; 2000. p. 114-22.

21. Spielberger CD. Manual for the state-trait anxiety inventory. Palo Alto, CA: Consulting Psychologists Press, Inc.; 1983.

22. Kardash VV, Kardash NI. Differential diagnosis of neurosis. Lutsk: Vezha; 2000. p. 65-8.

23. Beck AT, Steer RA, Garbin MG. Psychometric properties of the Beck Depression Inventory: Twenty-five years of evaluation. Clin Psychol Rev. 1988;8:77-100.

24. Kardash VV, Kardash NI. Conceptual and methodological problems in anxiety assessment. Lutsk: Vezha; 2003. p. 12-24.

25. Frasure-Smith N, Lesperance F, Talajic M. Depression and 18month prognosis after myocardial infarction. Circulation. 1995;91:999-1005.

26. Denollet J. Emotional distress and fatigue in coronary heart disease: the Global Mood Scale (GMS). Psychol Med. 1993;23:111-21.

27. Hevey D, McGee HM, Horgan J. Responsiveness of health-related quality of life outcome measures in cardiac rehabilitation: comparison of cardiac rehabilitation outcome measures. J Consult Clin Psychol. 2004;72:1175-80.

28. Lowe R, Norman P, Bennett P. Coping, emotion and perceived health following myocardial infarction: concurrent and predictive associations. Br J Health Psychol. 2000;5:337-50. 
29. Tucker LR, Lewis C. A reliability coefficient for maximum likelihood factor analysis. Psychometrika. 1973;38:1-10.

30. Bentler PM. Comparative fit indexes in structural models. Psychol Bull. 1990;107:38-246.

31. Brown MW, Cudeck R. Alternative ways of assessing model fit. In: Bollen KA, Long JS, editors. Testing structural equation models. Newbury Park, CA: Sage; 1993. p. 445-55.

32. Briggs SR, Cheek JM. The role of factor analysis in the development and evaluation of personality scales. J Person. 1986;54:106-48.

33. Clark LA, Watson D. Constructing validity: basic issues in objective scale development. Psychol Assess. 1995;7:309-19.

34. Whitehead DL, Perkins-Poras L, Strike PC, Magid K, Steptoe A. Cortisol awakening response is elevated in acute coronary syndrome patients with type-D personality. J Psychosom Res. 2007;62:419-25.

35. Lesperance F, Frasure-Smith N. Negative emotions and coronary heart disease: getting to the heart of the matter. Lancet. 1996;347:414-5.

36. Smith TW, MacKenzie J. Personality and risk of physical illness. Ann Rev Clin Psychol. 2006;2:435-67.

37. Spindler H, Pedersen SS, Serruys PW, Erdman RAM, van Domburg RT. Type D personality predicts chronic anxiety following percutaneous coronary intervention in the drug-eluting stent era. J Affect Disord. 2007;99:173-9.

38. Chapman BP, Duberstein PR, Lyness JM. The distressed personality type: replicability and general health associations. Eur J Pers. 2007;21:911-29. 